\title{
Neighbourhood Nuisances in The Bahamas: The Case of New Providence
}

\author{
Cassandra R. Adderley ${ }^{1}$
}

\begin{abstract}
This paper discusses the issue of neighbourhood nuisances in The Bahamas using New Providence as a case study. Despite there being a legal framework that defines actions which are classified as nuisances, and thereby defines actions which are illegal, it is apparent that most residents suffer from nuisances in their neighbourhoods. Results from a convenience sample of 414 adults living in New Providence show that residents are very tolerant to nuisances and rarely involve the police, even when the activity is criminal. It is hypothesised that residents' tolerance to nuisances arises from a complex interaction of innate tolerance, apathy and a feeling that the police are ineffective. In common with studies done elsewhere, noise was the biggest nuisance to most people; this may suggest that revised legislation is required to mitigate this pervasive social ill.
\end{abstract}

\section{INTRODUCTION}

A review of the literature revealed that no research had been done in The Commonwealth of The Bahamas on neighbourhood nuisances, notwithstanding the fact that there is a weekly column in The Tribune newspaper, which allows readers to explain, "Why you vex?" Elsewhere, communities have websites and restrictions of many activities, which may interfere with their neighbour's enjoyment of their property. The City of Sacramento (2006) has a neighbourhood code enforcement that handles "community and neighborhood nuisances such as illegal dumping, abandoned or inoperable vehicles, graffiti and zoning violations” (para. 1).

All persons, because of their cultural background, upbringing, environment, socio-economic status, i.e. whether they have the means to do something about a nuisance, etc., have different ideas of what constitutes a nuisance. One definition of a nuisance is, "one that is annoying, unpleasant, or obnoxious” (Merriam-Webster, 2003, p. 850). However, as many nuisances are specifically covered by the law, the legal definition of a nuisance as "something (as an act, object, or practice) that invades or interferes with another's rights or interests (as the use or enjoyment of property) by being offensive, annoying, dangerous, obstructive, or unhealthful," is important (Merriam-Webster, 1996, p. 333). The three statutory provisions in The Bahamas covering nuisances are the Penal Code (1927), Dog Licence Act (1942) and Environmental

\footnotetext{
${ }^{1}$ Cassandra R. Adderley, Paralegal/Compliance Officer, Callenders \& Co. Counsel and Attorneys, One Millars Court, PO Box N-7117 Nassau, Bahamas.

Acknowledgments: The author is grateful to the students of SOS 200 Social Research class Fall 2006 at The College of The Bahamas (which included the author) for collecting the data and for their input into the content of the survey form. The author also wishes to thank William J. Fielding, Director of Planning at The College of The Bahamas, for focusing the author's attention on the treatment of nuisances under Bahamian law.

Note: This paper is based upon a research project completed during Fall 2006.

E-mail: cadderley@callenders-law.com

How to cite this article in APA ( $5^{\text {th }}$ ed. Style): Adderley, C. R. (2008). Neighbourhood nuisances in The Bahamas: The case of New Providence. The College of The Bahamas Research Journal, 14; 4-12. Retrieved from http://researchjournal.cob.edu.bs
} 
Health Act (1987) with the Penal Code listing various nuisances under Title XV "Common offences against public order, health and morality”.

In law, consideration is given to the question of whether there were any differences in the standard of proof with respect to what is a nuisance under statute law and common law. Statute laws are laws enacted by the state, while common laws are laws that are established by rulings handed down by judges based on the history of the issue at law, i.e. whether the point of law has already been decided by a prior case, serve as precedents and are applied to cases that are not covered by statute. According to Elliott and Quinn (1996) nuisances can be classified into two common law categories; (a) private nuisances which is, “... an unreasonable interference with another's use or enjoyment of land, and therefore cases usually arise from disputes between owners of adjacent land;" (p. 88) and (b) public nuisances, an activity "...which materially affects the reasonable comfort and convenience of life of Her Majesty's subjects. It therefore covers activities which endanger or interfere with the safety or comfort of a section of the public, or which prevent them from exercising their rights." (p. 94) "Statutory nuisances “... have replaced common law provisions on nuisances in that area. In determining the scope of these nuisances regard must be had to the specific legislative provisions". (p. 95)

Although a nuisance can be defined, once it occurs between neighbours, it often affects the relationship between individuals, who are unrelated, and those neighbours at the time the nuisance occurs, are not concerned with what someone else considers or defines as a nuisance, but rather what effect the nuisance is having on them at that particular time. In a study on neighbourhood nuisances Paquin and Gambrill (1994) found this to be true. "When a dog barks for 2 hours, an individual is likely to have to think about the annoyance for at least 2 hours...” (p. 31) Nuisances can also cause stress, which can lead to a legal confrontation between close neighbours, "Neighbours are an unavoidable facet of urban environments. The very nature of urban life lends itself to irritation between neighbours - those unrelated individuals who live in close physical proximity to each other". (p. 21) Neighbours were also found to be an irritant in The Bahamas. In a Supreme Court case, Wells v. Knowles, 2003 a cause of action (tort) was brought under common law on legal nuisance. The plaintiffs in this case sought damages for harassment and loss of quiet enjoyment of their property as well as damages for loss of consortium. The evidence on the loss of consortium reported that the plaintiffs were "unable to function sexually as a result of the effect of the behaviour of the defendants on them". (paras. 2, 20, \& 28) Evidence was also presented in this case by one of the plaintiffs "that the stress created from the behaviour of the defendants reduced her capacity to work and thus reduced her income" (para. 29). Bijsterveld (2003) also reported that in The Netherlands, "The noisy neighbour was hardly a new phenomenon. Local ordinances aimed at regulating noise, including that of next door's crowing cocks and barking dogs, date back to medieval times - and some even to antiquity.”. (p. 173) Obviously, nuisances can be minor irritations as well as major life stressors. There exists very little literature on neighbourhood nuisances in The Commonwealth of The Bahamas. To determine how common neighbourhood nuisances are in Bahamian neighbourhoods and people's reactions, a study of residents in New Providence was conducted in Fall 2006.

\section{METHODS}

The topic of nuisances was discussed over a period of time in a social research class at The College of The Bahamas to determine what Bahamians considered as nuisances so that a survey could be designed that was relevant to The Bahamas. Over a one-month period, radio talk shows, such as "Real Talk Live" and "Issues of the Day" were monitored, and articles in the daily newspapers were reviewed, in particular, the "Why you vex?" column in The Tribune, to answer the question of what were considered nuisances by Bahamians. Complaints to the police were also consulted to ensure that the list was as comprehensive as possible. Items included on the list had to conform to the dictionary definition of nuisance and had to have been 
caused by neighbours, so natural nuisances, such as flooding were ineligible. Nuisances that were clearly criminal activities (such as burglary) were also omitted. This approach resulted in a list of 29 nuisances presented in Table 1 . Respondents were also asked to nominate their single biggest neighbourhood nuisance and what they would do about it, either nothing, do something (such as talk to the person causing the nuisance) or call the police.

The initial objective was to survey 500 Bahamians, 250 males and 250 females, over 18 years of age, using a convenience sample. The target population was limited to Bahamians as it was thought that culture and heritage might influence perception and so make interpretation more difficult if the target population were not focused. The rationale for interviewing an equal number of males and females was to obtain a representative sample of the make-up of the Bahamian population, as the Report on the 2000 Census of Population and Housing (2002) indicates that males and females are almost equally represented in the total population of The Bahamas. Only adults, over 18 years of age were included so that parental consent would not be required. Participants were interviewed across the island in places where they would be expected to have to wait, and this aspect was deliberately chosen so as to enhance participation

Respondents were asked whether their households had air-conditioning, and owned a motor vehicle in order to triangulate the sample and assist with the interpretation of the data.

\section{RESULTS}

Four hundred and fourteen persons were surveyed, 210 females and 202 males (one survey did not indicate sex and one survey had been entered incorrectly) and of those 414 persons, 209 were under 35 years of age and 205 were 35 years of age or over $(N=414)$. Respondents lived in approximately 122 subdivisions and residential neighbourhoods of New Providence from Victoria Avenue in the North to Marshall Road in the South to Twynam Heights in the East and Tropical Gardens in the West. These neighbourhoods varied in their socio-economic status from Bain Town, which is considered lower income, to Gleniston Gardens, which is considered middle income to Westridge Estates, which is considered affluent.

Of the persons surveyed, $92.98 \%(n=384)$ owned motor vehicles and $7.02 \%(n=29)$ did not own a motor vehicle (one person did not answer this question); and $82.36 \%(n=341)$ persons indicated that their household had air-conditioning and $17.64 \%(n=73)$ did not have air conditioning. The study revealed that $39.6 \% \quad(n=164)$ of respondents lived in dog-owning households and $60.14 \%(n=249)$ did not own a dog (one respondent did not answer this question). The median number of years persons surveyed were resident in their neighbourhood was 10 years (range 1.5 months to 50 years).

\section{MOST COMMON NUISANCES}

The most common nuisances reported were dogs followed by noises (including barking dogs). (See Table 1.)

Table 2 indicates the frequency of the themed "single biggest nuisance" reported by respondents and their reactions to the nuisance. Only 5.8\% of respondents reported no nuisance in their neighbourhood. Noises were the most important nuisances, followed by general nuisances due to dogs, uncollected garbage and traffic. One respondent even reported that their son's loud music was the single biggest nuisance for them. Overall, there was a reluctance to report nuisances to the police. However, respondents were more likely to report the nuisance to the police if it involved general or traffic noise. When litter/dumping were reported as the most common nuisances they were likely to be reported to the police. However, it should be noted that litter/dumping was only a nuisance to $2.8 \%$ of respondents. Respondents were least likely to involve the police with regard to dogrelated nuisances. The "other" group of nuisances included criminal activities (such as burglaries, thefts, car break-ins), loitering, power outages, rats, smoking, bad roads, flooding, and legal and illegal immigrants, and only approximately onefifth of respondents who listed "other" nuisances were willing to call the police for these nuisances. 
Of those surveyed, $56.52 \%(n=234)$ of the respondents reported that they would do nothing about the nuisance with $30.92 \% \quad(n=128)$ reporting that they would do something (such as talk to the person causing the nuisance) and only
8.94\% ( $n=37)$ reported that they would call the police. Fifteen (3.62\%) respondents did not answer this question.

Table 1: Number of respondents reporting each item a nuisance and its level of frequency

\begin{tabular}{|c|c|c|c|c|}
\hline \multicolumn{5}{|c|}{ Frequency with which this item is usually a nuisance } \\
\hline Item & Not a nuisance & $\begin{array}{l}\text { About once a month } \\
\text { (rarely) }\end{array}$ & $\begin{array}{l}\text { Every week or so } \\
\text { (quite often) }\end{array}$ & $\begin{array}{c}\text { More than once a } \\
\text { week (often) }\end{array}$ \\
\hline Dogs barking at night & 125 & 95 & 80 & 114 \\
\hline Roaming dogs on your property & 150 & 81 & 82 & 101 \\
\hline Car sound systems + & 155 & 90 & 80 & 87 \\
\hline Unsupervised children* & 191 & 73 & 73 & 76 \\
\hline Loud motorbikes (in convoy) + & 174 & 98 & 71 & 71 \\
\hline Litter & 186 & 74 & 84 & 70 \\
\hline Noisy neighbours in the street & 199 & 91 & 61 & 63 \\
\hline Bad parking* & 216 & 74 & 60 & 63 \\
\hline Car horns & 203 & 85 & 66 & 60 \\
\hline Car alarms & 187 & 93 & 76 & 58 \\
\hline $\begin{array}{l}\text { Domestic noise (includes noises coming from } \\
\text { within a home, music etc.) }\end{array}$ & 179 & 111 & 67 & 57 \\
\hline Uncollected garbage & 123 & 112 & 124 & 55 \\
\hline Unkempt yards/gardens* & 201 & 12 & 59 & 51 \\
\hline Car pollution & 226 & 80 & 55 & 51 \\
\hline Firecrackers* & 181 & 124 & 58 & 50 \\
\hline Uninvited strangers calling at home & 228 & 106 & 32 & 48 \\
\hline Lawn mowing on Sunday mornings & 253 & 79 & 40 & 42 \\
\hline Dogs barking during the day & 227 & 103 & 42 & 42 \\
\hline Abandoned cars & 245 & 92 & 40 & 37 \\
\hline Beggars or "Jonsers" & 257 & 76 & 48 & 33 \\
\hline Neighbours' parties after midnight* & 189 & 150 & 43 & 31 \\
\hline Gangs & 264 & 80 & 42 & 27 \\
\hline Dumping (fridges etc) & 259 & 86 & 44 & 25 \\
\hline Overflowing sewerage & 298 & 62 & 30 & 24 \\
\hline Graffiti* & 271 & 78 & 40 & 24 \\
\hline Noise from air condition units & 324 & 44 & 26 & 20 \\
\hline Bonfires* & 290 & 65 & 40 & 18 \\
\hline Construction work/workers & 280 & 82 & 35 & 17 \\
\hline \multirow[t]{2}{*}{ Threatening telephone calls } & 350 & 36 & 13 & 15 \\
\hline & $n=414$ & $+n=412 \quad{ }^{*} n=413$ & & \\
\hline
\end{tabular}


Table 2: Themed "single biggest nuisance" in respondent's neighbourhood $(n=414)$.

\begin{tabular}{|c|c|c|c|c|c|c|}
\hline \multicolumn{7}{|c|}{ Reaction to nuisance (\% reporting nuisance) } \\
\hline & $\mathrm{N} / \mathrm{A}$ & Do nothing & Do something & Call police & $\mathrm{N}$ & $\%$ Total responses \\
\hline Noise, general & 2.1 & 60.4 & 24.2 & 13.2 & 91 & 21.9 \\
\hline Dog, general & .01 & 57.4 & 37.0 & 5.5 & 54 & 13.4 \\
\hline Dogs, noise & & 71.0 & 29.0 & 0.0 & 38 & 9.1 \\
\hline Uncollected garbage & & 56.3 & 43.7 & 0.0 & 32 & 7.7 \\
\hline Traffic, general & & 54.2 & 45.8 & & 24 & 5.8 \\
\hline No nuisance & 100.0 & 0.0 & 0.0 & 0 & 24 & 5.8 \\
\hline Noise, traffic & & 86.4 & 0 & 13.6 & 22 & 5.3 \\
\hline Unsupervised children & & 37.5 & 50.0 & 12.5 & 16 & 3.9 \\
\hline Litter/dumping & & 25.0 & 41.7 & 33.3 & 12 & 2.8 \\
\hline Unkempt yards/vacant lots & & 58.4 & 33.3 & 8.3 & 12 & 2.8 \\
\hline Beggars or "Jonsers" & & 36.3 & 54.5 & 9.0 & 11 & 2.6 \\
\hline Others & & 52.2 & 33.3 & 14.4 & 69 & 16.7 \\
\hline
\end{tabular}

\section{DISCUSSION}

It should be explained that the results from this study might contain a bias as they were obtained from a convenience sample of residents on New Providence.

It is clear that nuisances are widespread in neighbourhoods and that few residents are immune from this stress. Noises, dogs and uncollected garbage constitute the most common and pervasive nuisances. Noise and dogs, in particular their barking, have been found to be problems in neighbourhoods elsewhere (Bijsterveld, 2003; Paquin \& Gambrill, 1994), so these issues should not be viewed as unique to The Bahamas. However, what appears to distinguish the Bahamian community from other communities is the reluctance of the residents to effectively address the problems. In the case of dogs, this nuisance has been well documented in The Bahamas as far back as the 1840s (Fielding, Mather \& Isaacs, 2005). However, Paquin and Gambrill (1994) reported that a neighbour's barking dog is the most annoying nuisance. In "Why you vex?" Rolle (2006) reported a complaint as follows: "I vex with my neighbours. They can never dispose of their garbage properly and the dogs are always toting the pampers in my yard. That is just disgusting and nasty. In fact I tried talking to them and they just cussed me out" (p. 5A). This comment highlights several points: (a) both parties are probably breaking the law-the owner of garbage must store it securely and the dog owner probably does not license the dog (very few dogs are licensed, Fielding, et al., 2005) and so it is illegal for the dogs to roam); (b) neither protagonist is willing to admit that both are at fault and resolve the dispute. The reluctance of residents to exert their lawful right to engage the police to enforce the law as it relates to criminal activities needs further investigation.

The nuisance can also be a nuisance under common law or statute law. The nuisances examined in this study can be categorized either by definition of a nuisance or by falling under common law or statute law. Wambaugh (1914) described a nuisance as a "somewhat hazy sort of a wrong. And what a hazy sort of a wrong it is. The word "nuisance" means absolutely nothing but annoyance" (p. 147).

Noise (the number one nuisance) under the Penal Code (1927) is a summary offence and a common nuisance, and a cause of action might be found under common law for noise as a nuisance that interferes with ones enjoyment or quiet and affects the senses if the average man finds it objectionable (Clerk, Lindsell \& Brazier, 1995). However, the courts in considering whether the noise caused by a neighbour is actionable under the tort of nuisance will weigh the right of the 
plaintiff for peace and quiet against the defendant's use and enjoyment of his property. Therefore the effort involved for someone who brings suit under common law as opposed to a prosecution by the state under a statute might deter an individual from pursuing an action.

Civil society views nuisances as affecting the quality of life and society's solution to a nuisance is to enact legislation against nuisances. Wambaugh (1914) said that:

This law of nuisance, by the way, is only one of at least four instances in which society has created and retained and developed powers which enable the world, as time passes, to be a good fit ... There must be rules to enable them to live comfortably and morally. There must be machinery whereby from time to time the need of today is met. (p. 49)

The Bahamas has also considered what is a "good fit" and has made rules to make living comfortable in The Bahamas. The Dog Licence Act (1942) clearly gives any peace officer the authority to seize any licensed and unlicensed dog if it is found on any road or other public place between the hours of 10.00 p.m. and 6.00 a.m. The penalty for allowing a dog to stray unto a highway or other public place is only $\$ 4.00$ for a dog and $\$ 16.00$ for a bitch. If the bitch has been spayed the fee is $\$ 4.00$ (s. 11, para. 3). The Penal Code (1927) also states that stray dogs are illegal and provides that any complaint of a dangerous dog should be dealt with either by the dog being "kept by the owner under proper control or destroyed...” (s. 161). It quite clearly grants any peace officer the authority to seize any licensed and unlicensed dog if it is considered a danger and if it strays onto any road or other public place (s. 162). However, other than destruction of the dog, the penalty for "suffering ferocious dogs to be at large,” is only $\$ 100$ (s. 163).

Uncollected garbage was also another important nuisance for $7.72 \% \quad(n=32)$ of respondents, although it occurred more than once a week for only $13.28 \% \quad(n=55)$ of respondents. The Bahamas has also legislated against this nuisance and s. 9 of the Environmental Health Services Act
(1987) states that, "No person shall create or allow to exist on or emanate from premises which he owns or occupies conditions which are unsanitary or constitute a nuisance or are conducive to the breeding or harbouring of rodents, insect pests, termites or other vermin." (s. 9, para. 1). Again another example of a nuisance that is clearly against the laws of The Bahamas and the results of this study suggest that nothing substantial is done to resolve the nuisance. However, garbage collection from residential homes is carried out exclusively by the Department of Environmental Health, which has a Director, who is empowered by the Environmental Health Services Act of 1987 to prevent garbage from becoming a nuisance. Therefore, it appears that the Department of Environmental Health may be contributing to the garbage nuisance by not collecting the garbage in a timely manner.

The Penal Code (1927) has also made many nuisances illegal, although they are called by different names, such as shouting (noisy neighbours) or blowing horns, etc., in specified public places (car horns), permitting a disturbance (unsupervised children), making fire in town (bonfires), peddling and hawking (uninvited strangers calling at home), begging, and other noises (loud motor bikes, car sound systems, car alarms and firecrackers). Because these offenses are summary offenses the penalty is only a fine of \$150.00. The Environmental Health Act (1987) also considers dumping and littering in public places or open spaces as an offence and also places the onus of the homeowner to keep their verges abutting their premises clean and litter free (unkempt yards/gardens) (s. 9, paras. $2 \& 3$ ). The penalty for contravening the provisions of the Environmental Health Act (1987) upon the first summary conviction is a fine of $\$ 1,000.00$ or imprisonment for a term not exceeding nine months or both (s. 20, para. 1).

A review of court cases revealed very few instances of private nuisances being brought to court under common law and as shown in the case of Wells v. Knowles, 2003 it was only when life became intolerable that the plaintiffs decided to institute a cause of action under tort law. Because 
offenses committed under the Dog Licence Act (1942) and the Penal Code (1927) are summary offenses (tried in a magistrate's court and not the Supreme Court) these cases are not reported in law reports and due to time constraints it was decided not to review court files.

A lack of knowledge of the law might be a reason people do not complain about dogs (Fielding, 2007) or noise. A second possibility might be that the respondents were aware of their legal rights but believed it would be too difficult to enforce the law because of the subjective nature of the nuisances. A third possibility might be that the respondents were not aware of their legal rights. A fourth possibility could be that the respondents did not wish to create any hard feelings or difficulties with their neighbours.

The Bahamas has considered replacing at least one of its statute laws dealing with nuisances and legislation has been drafted to replace the Dog Licence Act of 1942. The Bahamas Humane Society is hopeful that the new act to be called "The Animal Protection and Control Act", which is presently under review at the office of the Attorney-General, will be passed sometime in 2007 (Outten, 2006, p.A10).

Even today the nuisances discussed by Wambaugh (1914) are still relevant and he concludes:

that our successors will be as wise as we and that they will not go too far, and that they too will apply fairly to the needs of their place and time all the humanizing and civilizing powers which have existed so long, and, more specifically, the essential doctrines of this law of nuisance - the doctrines that a private individual may not use his property or his liberty in such a way as to do any substantial damage to his neighbours or to the whole community and that he must conduct his business, however useful it may be, in a way that is reasonable. (p. 149)

Enacting legislation to control nuisances is also not unique to the Bahamas. The Netherlands also has a law on nuisances. Bijsterveld (2003) wrote:
Since 1881, the penal code had included two sections on disturbance. The most important one was s. 431, which stipulated that it was illegal to disturb people's sleep at night, be it through disturbances that threatened the peace of one's immediate neighbours or through disturbances that broke the quiet of a complete neighbourhood. (p. 177)

Another community coping with nuisances is the city of Charleston, South Carolina. Jonsson (2002) reported that Charleston has a "livability court" where quality of life issues that include "unkempt yards to the unpleasant smell of sewage," which are considered "minute misdemeanours that seem trivial to all but those experiencing these every day nuisances," are adjudicated by a judge (p. 1). Jonsson further reported that the judge in the livability court decided that a county jail work crew would trim a lot owned by a doctor who would not cut his lawn. This doctor had lived in his home for 51 years and it appeared that the lawn had not been cut in those 51 years.

Nuisances can sometimes become so unbearable that although the majority will do nothing about them, some will seek relief from the law. In the case of Wells v. Knowles, 2003 the plaintiffs resorted to tort law (they sued for loss of consortium), a private nuisance as defined by Elliott and Quinn (1996), to receive relief from their neighbour and the judge granted them relief by issuing, “... an injunction against Rosemarie Knowles restraining her from harassing, communicating with, lodging complaints about or pestering the plaintiffs in any way, which is to remain in effect unless varied or lifted by this Court" (Wells v. Knowles, 2003, para. 155). The judge held that there was no evidence that the nuisance created by the defendant led to the plaintiffs' loss of consortium.

Another example of an unbearable nuisance was reported by Lowe (2006), in The Tribune, when it was alleged by a resident that her neighbour had "made threats and invaded their property repeatedly over a period of at least seven years" (p. 2A). This story had elements of several of the 
nuisances considered by this study. The story reported that the offender had placed a dead dog under the complainant's window, shouted obscenities, started fires, entered her property, peeked at her through her windows and "spread things across the yard". The only solution to this complainant's nuisance was the press, because she stated that she had reported the offender to the police and the police had done nothing.

Another matter to consider as to why the majority of respondents did not believe they had neighbourhood nuisances might be the number of households that had air conditioning. Of those surveyed, $82.36 \%(n=341)$ persons confirmed that their household had air conditioning and $17.64 \%$ $(n=73)$ did not have air conditioning. The use of air conditioning would have insulated the respondents from noise outside of their homes and, therefore, the nuisances did not affect them. Household ownership of air conditioning is also an indicator of affluence and arising out of this affluence might be the respondents' perception that if the problem were a big enough nuisance, they had the economic wherewithal to alleviate the problem. Another indication of the economic wherewithal to alleviate the problem is car ownership. According to the Bahamas Living Conditions Survey, 2001 (2004) the, "Residents of New Providence ... who enjoy the highest standard of living, comprise $85 \%$ of the country's population...” (p. xxi). Paquin and Gambrill (1994) reported that:

Upper middle class individuals are likely to ignore or minimize problems between neighbours, perhaps because their pursuits carry them far beyond the confines of home for extended periods, or because they feel confident that they have the resources to protect their interest should they need to. (p. 23)

Paquin and Gambrill (1994) also reported that “...many respondents minimize the importance of such annoyances” (p. 31). Perhaps the respondents in this study are also minimizing the annoyances.

The number of years persons surveyed were resident in their neighbourhood did not appear to have affected the type of nuisance reported or its frequency.

One answer provided for the single biggest nuisance was "my son's loud music." This is of interest because the study did not consider that a member of the respondent's immediate household could be a nuisance. This, perhaps could be further explored in another study.

Although approximately 122 neighbourhoods and residential areas were surveyed, the study did not determine the socio-economic level of the neighbourhoods and residential areas. Only two questions relating to affluence were included and these were households having air conditioning and households owning a car. The socio-economic level of the neighbourhoods and residential areas might have influenced the results of this study and, again, further exploration might prove productive.

In conclusion the results discovered that the single biggest neighbourhood nuisances in The Bahamas are attributable to noises, including dogs. It is possible that the passing of the Animal Protection and Control Act will alleviate the direct effects of the nuisances caused by dogs, since the Dog Licence Act (1942) and the Penal Code (1927) have not done so, perhaps because the penalties imposed under these two Acts for contravening the provisions are now considered inconsequential both to those who break the law and to those charged with enforcing it.

Another consideration that emerged from this study is why such a large number of respondents chose not to do anything about the nuisance. An answer to this might be because the island of New Providence is very small ( 7 miles by 21 miles) and is home to an extremely close knit society, where everyone knows everyone, and maybe this close proximity deterred neighbours from creating or seeming to create ill will by trying to alleviate the nuisance. This aspect is worthy of further research, as it may hold the key to society finally ridding itself of neighbourhood nuisances. 


\section{REFERENCES}

Bijsterveld, K. (2003). 'The City of Din’: Decibels, noise, and neighbors in the Netherlands, 19101980. Osiris. 18, 173-193.

City of Sacramento. Code Enforcement Department. (2006, September 20). Neighborhood code enforcement. Retrieved December 19, 2006, from www.cityofsacramento.org/code/nce.html

Clerk, J. F., Lindsell, W. H. B., \& Brazier, M. (1995). Clerk \& Lindsell on torts. (17 ${ }^{\text {th }}$ Ed.). London: Sweet \& Maxwell.

Department of Statistics. (2002). Report on the 2000 census of population and housing. Nassau: Ministry of Economic Development.

Department of Statistics. (2004). Bahamas living conditions survey, 2001. Nassau: Author.

Dog Licence Act, 1942, [CH. 378], (Bahamas).

Elliott, C., \& Quinn, F. (1996). Tort law. London: Longman.

Environmental Health Services, 1987, [CH. 232], (Bahamas).

Fielding, W. J. (2007). Knowledge of the welfare of nonhuman animals and prevalence of dog care practices in New Providence, The Bahamas. Journal of Applied Animal Welfare, 10(2), 153168. doi: 10.1080/10888700701313587

Fielding, W. J., Mather, J., \& Isaacs, M. (2005). Potcakes: Dog ownership in New Providence, the Bahamas. West Lafayette, Ind: Purdue University Press.

Jonsson, P. (2002, January 30). Dog barking late? I’ll see you in livability court. Christian Science Monitor, 94(46), 1. Retrieved from EbscoHost Academic Search Complete database.

Lowe, A. (2006, September 28). Woman complains that police have not dealt with dangerous neighbour. The Tribune, p. $2 \mathrm{~A}$.

Merriam-Webster's collegiate dictionary. (2003). (11 ${ }^{\text {th }}$ Ed.).Springfield, Mass: Author.

Merriam-Webster's dictionary of law. (1996). Springfield, Mass: Author.
Outten, L. (2006, September 20). BHS hopes pet laws are fixed. The Nassau Guardian, p. A10.

Paquin, G.W. \& Gambrill, E. (1994). The problem with neighbors. Journal of Community Psychology, 22(1), 21-32. Retrieved from EbscoHost Academic Search Complete database.

Penal Code, 1927, [CH. 84], (Bahamas).

Rolle, K. (2006, November 6). Why you vex? The Tribune, p. 5A.

Wambaugh, E. (1914). Nuisances under the law. American Journal of Public Health, 4(2), 145-49. Retrieved from the Pubmedcentral database.

Wells v. Knowles, 170, BHSJ (2003, November 25). Retrieved from Quicklaw database. 